\section{Role of verocytotoxigenic Escherichia coli in the swine production chain}

\author{
Laura Ercoli, ${ }^{1}$ Silvana Farneti, ${ }^{1}$ \\ David Ranucci, ${ }^{2}$ Stefania Scuota, ${ }^{1}$ \\ Raffaella Branciari ${ }^{2}$ \\ 'Institute for Experimental Veterinary \\ Medicine of Umbria and Marche, Perugia; \\ 2Department of Veterinary Medicine, \\ University of Perugia, Italy
}

\section{Abstract}

Shiga toxin-producing Escherichia coli (STEC) can cause severe clinical diseases in humans, such as haemorrhagic colitis (HC) and haemolytic-uremic syndrome (HUS). Although ruminants, primarily cattle, have been suggested as typical reservoirs of STEC, many food products of other origins, including pork products, have been confirmed as vehicles for STEC transmission. Only in rare cases, pork consumption is associated with severe clinical symptoms caused by high pathogenic STEC strains. However, in these outbreaks, it is unknown whether the contamination of food products occurs during swine processing or via cross-contamination from foodstuffs of different sources. In swine, STEC plays an important role in the pathogenesis of oedema disease. In particular a Shiga toxin subtype, named $s \mathrm{x}_{2 \mathrm{e}}$, it is considered as a key factor involved in the damage of swine endothelial cells. On the contrary, stx 2e $_{\mathrm{e}}$-producing Escherichia coli has rarely been isolated in humans, and usually only from asymptomatic carriers or from patients with mild symptoms, such as uncomplicated diarrhoea. In fact, the presence of gene $s t x_{2 e}$, encoding for $s t \mathrm{x}_{2 \mathrm{e}}$, has rarely been reported in STEC strains that cause HUS. Moreover, st $_{2 \mathrm{e}}$-producing STEC isolated from humans and pigs were found to differ in serogroup, their virulence profile and interaction with intestinal epithelial cells. Because of the limited epidemiologic data of STEC in swine and the increasing role of non-0157 STEC in human illnesses, the relationship between swine STEC and human disease needs to be further investigated.

\section{Introduction}

Escherichia coli is a Gram-negative microorganism belonging to the Enterobacteriaceae family, which is usually found, as commensal, in the enteric tract of many animal species. However, several E. coli strains can cause a wide range of clinical symptoms in humans and animals, due to the expression of particular virulence factors, whereby Escherichia coli strains have been classified in different pathogroups (Gyles, 2007).

The pathogroup of Shiga toxin-producing Escherichia coli (STEC or VTEC) is characterised by the production of one or both cytotoxins, known as Verotoxins or Shiga toxins (Stx1 and Stx2). Stx1 and Stx2 are immunologically distinct. In fact, they have approximately $56 \%$ of the amino acid sequence in common. Shiga toxins are encoded by genes $s t x 1$ and $s t x 2$ - generally carried by prophages; $s t x$ gene expression occurs when the lytic cycle of the phage is induced (Bergan et al., 2012).

Several variants of both Shiga toxins have been identified. According to the nomenclature system Scheutz et al. (2012) proposed, Stxl subtypes found in $E$. coli are designed as Stxla, Stxlc, and Stxld, whereas Stx2 consists of seven variants, indicated from Stx2a to Stx2g. STEC strains can express a combination of one or more stx subtypes (Karve and Weiss, 2014). However, epidemiological studies have shown that Stx2 is more associated with severe human disease than is Stxl, and strains producing Stx2a and Stx2c seem to be more commonly isolated in patients with HUS than are those producing other Stx variants (Caprioli et al., 2005). Moreover, some Stx2 variants are often produced by strains of animal origin and are occasionally found in human isolates: stx $_{2 \mathrm{e}}$ is mainly observed in pigs and $s_{2 \mathrm{f}}$ is described, especially in strains of avian origin (Caprioli et al., 2005). However, to understand the role of these strains as human pathogens, further studies are needed (Friesema et al., 2014).

Unlike cattle that do not typically have any STEC-associated symptoms (Tseng et al., 2014a), swine may present clinical disease due to STEC infection (Tseng et al., 2014b). Oedema disease, an infectious illness that often affects post-weaning piglets and young finishing-age pigs, is caused by $E$. coli strains harbouring the $s t x_{2 e}$ gene, encoding $s \mathrm{x}_{2 \mathrm{e}}$. In several countries, cross-sectional epidemiological studies have been conducted on the prevalence of STEC in clinically healthy swine. STEC prevalence ranges from $0 \%$ to $68.3 \%$ (Tseng et al., 2014b). Studies about prevalence of STEC 0157:H7 in the United States estimate low values, ranging from $0 \%$ to $1.9 \%$. In a more recent survey, STEC strains were isolated from $65.3 \%$ of faecal samples collected from pigs during the finishing period. Most of the STEC isolates carried the $s t x_{2 e}$ gene (97.9\%) and belonged to serotype 059:H21 (73.6\%) (Tseng et al., 2014b). A study conducted in China reported a high prevalence of STEC (25.42\%) in healthy pigs found using PCR screening, although only $6.18 \%$ of the swine specimens gave a positive result by microbiological culture. All STEC iso-
Correspondence: David Ranucci, Department of Veterinary Medicine, University of Perugia, via San Costanzo 4, 06126 Perugia (PG), Italy Tel: +39.075.5857931 - Fax: +39.075.5857928.

E-mail: david.ranucci@unipg.it

Key words: Escherichia coli; STEC; Pig; Stx2e; PCR.

Conflict of interest: the authors declare no potential conflict of interest.

Received for publication: 14 March 2015. Revision received: 18 March 2015.

Accepted for publication: 18 March 2015.

This work is licensed under a Creative Commons Attribution 3.0 License (by-nc 3.0).

(C) Copyright L. Ercoli et al., 2015

Licensee PAGEPress, Italy

Italian Journal of Food Safety 2015; $4: 5156$

doi:10.4081/ijfs.2015.5156

lates harboured $s t x_{2 e}$ and none of the strains belonged to the top five serogroups (0:157, 0:145, 0:103, 0:111, 0:26) (Meng et al., 2014).

Many STEC that are highly pathogenic to human beings, included in the Enterohaemorrhagic E. coli group (EHEC), are often characterised by the production of an outer membrane protein called intimin. This protein mediates the attachment of bacteria to enterocytes and induces cytoskeletal changes, with accumulation of actin, causing characteristic histopathologic lesions, defined as attaching and effacing (A/E). Intimin encoding gene (eae), which belongs to a large pathogenicity island (PAI) called locus of enterocyte effacement (LEE), is an important additional virulence factor. Based on the amino acid sequence and antigenic differences, several intimin types have been identified: intimin $\alpha$ is generally found in Enteropathogenic $E$. coli (EPEC), intimin type $\gamma$ is often associated with highly pathogenic STEC serogroups such as $0: 157,0: 111$ and $0: 145$, and intimin $\varepsilon$ is produced by STEC 0:121 and 0:103. Intimin $\beta$ can be found in EPEC and STEC, in particular in EHEC 0:26 (Caprioli et al., 2005).

The presence of eae gene is strongly associated with some STEC serotypes (0157:H7, 0157:NM, 026:H11, 0111:NM, 0103:H2, 0121:H19, and 0145:NM) involved in outbreaks of $\mathrm{HC}$ and HUS. However, eae-negative strains, such as 091:H21, 0113:H21 and more recently 0104:H4, have been associated with serious disease, underlining the importance of other virulence factors (Bouvet et al., 2001, 2002a). Other factors located on mobile genetic elements, like PAI or plasmids, have been identified. Nevertheless, in some cases, their role in the pathogenic process has not been fully elucidated (Caprioli et al., 2005). A wide 
range of plasmidic putative virulence factors is described in STEC strains. The gene saa, which codifies for autoagglutinating adhesin Saa, has been found on the large plasmid in LEE-negative STEC strains (e.g., 0113:H21, 091:H2) (EFSA, 2007; Gyles, 2007). Synthesis and transport of enterohaemolysin are encoded by the hly operon, located on the large plasmid p0157, characteristic of STEC 0157 and some other STEC serogroups (Caprioli et al., 2005). The plasmid-encoded haemolysin can be produced by both eae-positive and eae-negative STEC (Gyles, 2007). Other putative virulence factors harboured by plasmid p0157 are comprised of catalase-peroxydase, encoded by the $k a t P$ gene, and a serine protease, encoded by the espP gene (Caprioli et al., 2005). Furthermore, different $E$. coli strains may belong to more than one pathotype group. For example, E. coli 0104:H4, involved in Germany's outbreak in 2011, was positive for Verocytotoxin 2 gene (stx2) and also harboured $a$ aiC and $\operatorname{agg} R$ virulence genes, which are typical of Enteroaggeregative $E$. coli (EAEC) (Frank et al., 2011).

STEC infections are reported in a wide range of both domestic and wild animal species (e.g., calves' dysentery, pigs' oedema disease, cutaneous and renal vasculopathy in Greyhound dogs), but human infections are relatively uncommon (Caprioli et al., 2005). In a report of the European Food Safety Authority (EFSA), the prevalence of STEC in overall EU is about 1.2 cases per 100,000 of the population (EFSA, 2007). STEC infection may result in severe illnesses, such as haemorrhagic colitis (HC) and haemolytic uraemic syndrome (HUS). Children less than five year years of age and the elderly are especially susceptible to severe complications (Gyles, 2007). The term Enterohaemorrhagic E. coli (EHEC) indicates the subset of STEC strains that has been firmly associated with these severe symptoms. In many countries, 0157:H7 is the serotype associated with most cases of disease, but outbreaks caused by non-0157 EHEC strains, like 026, 0111, 0103 and 0145, have been increasingly described (Caprioli et al., 2005).

In 2003, Karmali et al. proposed a STEC classification model, based on seropathotypes. This approach classifies STEC according to function of serotypes, frequency of involvement in outbreaks and disease incidence and severity. However, the 0104:H4 outbreak in 2011 demonstrated the difficulty of predicting the emergence of non-0157 pathogenic STEC strains by focusing on a restricted panel of serogroups. Because of the impossibility of clearly defining STEC seropathotypes, the EFSA BIOHAZ Panel made a series of recommendations relating to the public health investigation of STEC infections. A molecular approach, utilising genes encoding virulence characteristics in addition to the presence of stx genes in isolates from human, food and animal sources, is proposed (Eriksson et al., 2003).

STEC are zoonotic agents that can be transmitted to humans through person-to-person contact, ingestion of food or water contaminated with animal faeces, and by direct contact with animals (Caprioli et al., 2005; Smith et al., 2014). Although STEC have frequently been isolated from the intestinal content of a wide range of animal species, ruminants, especially cattle, are recognised as their main natural STEC reservoir. Cattle are usually asymptomatic excretors of the microorganism, which is a transient commensal member of the intestinal micro flora (Caprioli et al., 2005; Bolton, 2011). On the contrary, few epidemiologic data are available about monogastric animals and do not clearly elucidate the role of these species as a source of human pathogenic STEC (EFSA, 2007).

\section{Swine role in Shiga toxin-pro- ducing Escherichia coli epi- demiology}

In the scientific report of the European Food Safety Authority (EFSA) and European Centre for Disease Prevention and Control (ECDC) on trends and sources of zoonoses, zoonotic agents and food-borne outbreaks (EFSA and ECDC, 2015) in 2013, campylobacteriosis is the most commonly reported zoonosis, showing a stabilised trend of human case notification during the period of 2009-2013. The decreasing EU trend in confirmed human salmonellosis cases observed in recent years has continued, while human listeriosis has increased. Also, the number of confirmed verocytotoxigenic Escherichia coli infections in humans increased. In 2013, 6043 confirmed cases of STEC infections were reported in the $\mathrm{EU}$, with a notification rate of 1.59 cases per 100,000 population, which was $5.9 \%$ higher than in 2012. The most commonly reported serogroups in 2013 were 0:157, followed by $0: 26$. In Italy, 65 confirmed cases of human infections were reported in 2013, and 50 human cases were confirmed in 2012. STEC was also reported in the EU from food and animals. These data on STEC detection are collected annually on a mandatory basis by EU Member States (MS) to European Commission and EFSA, based on Directive 2003/99/EC (European Commission, 2003). Data on STEC detected in food confirm the important role of cattle as a source of food-borne STEC infections. In 2013, a total of 3898 fresh bovine meat samples and 860 raw milk specimens were tested, and $2.5 \%$ and $2.3 \%$, respectively, were STEC-positive. In addition, six MS (including
Italy) reported testing of 447 fresh pig meat samples from processing plants, retail venues and slaughterhouses, with no positive STEC findings. Regarding the detection of STEC from animal samples, just three MS (Italy, Germany and Netherlands) collected data on STEC in pigs and only Germany (17.0\% positive animals) and Netherlands (15.8\% positive pens) found STEC-positive results. The overall proportion of STEC-positive units was $16.7 \%$. This positivity rate is higher than data reported in cattle. The overall proportion of positive STEC units found by seven MS in cattle was $6.7 \%$. It is important to note that the MS to STEC detection from food and animals used different sampling strategies and analytical methods. Consequently, data from different investigations are not necessarily directly comparable (EFSA and ECDC, 2015).

Although cattle is suggested as the most important animal reservoir of STEC, very little is known about the occurrence of STEC in other domestic animals (Beutin et al., 1993). The prevalence of STEC in the swine population, the presence of STEC in pork products and the incidence of pork-associated STEC outbreaks have been reported in some epidemiologic studies in multiple countries. However, these data are sparse and not directly comparable. The discrepancies are attributable to several factors, such as the different study designs, the application of various sample collection methods or STEC detection and isolation protocols (Tseng et al., 2014b).

The occurrence of STEC in swine faecal samples varies with a wide range of values, depending on the study. In Europe, STEC detection in the swine population has been described in several countries. A study conducted in Belgium reported a high prevalence of STEC from individual rectal swabs (56/177, 31\%). In multiplex PCR, the serotype 0157, assayed using PCR of the $r f b E$ gene, was present in $30 \%(43 / 143)$ of tested swabs (Botteldoorn et al., 2002). Similarly, in France, about $31 \%$ (129/182) of faecal samples tested using PCR were stx-positive, but among the 129 positive specimens, none contained a detectable uidA gene from 0157:H7 (Bouvet $e t$ al., 2002b). In Switzerland, of 630 faecal samples collected at slaughter, $22 \%$ and $7.5 \%$ were positive using a PCR for $s t x$ and $r f b E$, respectively (Kaufmann et al., 2006). In a study conducted in northern Italy in 1993, faecal specimens from 242 slaughtered pigs were tested using the Vero cell assay, and the presence of STEC was assessed in 7.8\% (19/242) of enriched samples (Caprioli et al., 1993). Bonardi et al. (2003) performed a later study, which showed a low portion of STEC 0157-positive faecal samples in Italy. STEC 0157 was isolated from the intestinal content of one (0.7\%) of 150 tested pigs. Similarly, in a Dutch study, Heuvelink and colleagues (1999) isolat- 
ed $E$. coli 0157 strains from two rectal contents of 145 tested pigs (1.4\%), but only one $(0.7 \%)$ harboured the $s t x 2$ gene. In addition, as part of the national Dutch monitoring programme in farms, 1,122 pooled faecal samples were collected from 229 finishing pig herds and $0.4 \%$ (1/229) were found to have $E$. coli 0157 that was positive with the isolation methods (Schouten et al., 2005). A lower prevalence of STEC 0157:H7 was reported from pigs slaughtered at five Swedish facilities: STEC 0157:H7 was isolated from two of 2,446 individual faecal samples, indicating a prevalence of $0.08 \%$ (Eriksson et al., 2003). Beutin et al. (1993) analysed 120 swine faecal specimens collected in Germany and STEC was isolated from nine pigs (7.5\%), but none of the isolates belonged to the 0157 serogroup.

In the United States, STEC detection in the swine population has also been reported (Tseng et al., 2014a). A study was published in 2003 , in which colon samples were obtained from pigs at slaughter. Six (1.97\%) of the 305 colon samples gave isolates positive for $r f b_{0157}$ and $\mathrm{fli}_{\mathrm{H} 7}$ genes of the 0157:H7 serotype, as well as for stx genes (Feder et al., 2003). Interestingly, no STEC 0157:H7 strain was isolated in the National Animal Health Monitoring System's Swine 2000 study. In this study, out of a total of 687 swine faecal samples tested for the presence of $s t x 1$ and stx 2 using PCR assays, 484 (70\%) of the samples were positive for one or both genes and at least one STEC isolate was recovered from the 196 faecal samples (196/687, 28.5\%). It is noteworthy that about $80 \%$ of STEC isolates harboured $s t x_{2 e}$ and no strain of serogroup 0157 was found (Fratamico et al., 2004; Tseng et al., 2014a). A higher isolation rate was obtained in a longitudinal study, in which the STEC faecal shedding from the beginning to the end of the finishing period in 150 pigs was analysed. A total of 1,200 faecal samples were collected (eight collections for each pig) and STEC isolates were recovered in the last sample from $65.3 \%(98 / 150)$ of the pigs. Most of the STEC strains $(97.9 \%)$ carried the $s t x_{2 e}$ gene and $E$. coli 0157:H7 was not isolated (Tseng et al., 2014b). Also, in another study conducted in Chile, a high STEC prevalence was estimated. STEC strains were identified by DNA hybridisation in $68.3 \%(82 / 120)$ of the faecal samples of 120 healthy pigs (Borie et al., 1997). Otherwise, other South American studies reported lower values of STEC prevalence. In Brazil, one study estimated a prevalence of $1.35 \%(1 / 74)$, assessed by isolation of one $s t x 2$ positive strain from 74 swine intestinal samples (Martins et al., 2011). A later study, also performed in Brazil, used PCR to detect stx 2 or stx2 and eae genes in 40 of 226 faecal samples, but no STEC isolate was obtained (Borges et al., 2012).

The presence of STEC in swine populations was also documented in Asia (Tseng et al., 2014a). A Japanese national surveillance report stated that STEC isolates were recovered from 32 (14\%) of 179 faecal samples. Among the isolates, $s t x_{2 e}$ were dominant and serotypes frequently implicated in human diseases or eae-positive stains were not observed (Kijima-Tanaka et al., 2005; Tseng et al., 2014a). Out of 1003 samples (326 faecal specimens and 677 intestinal contents) analysed in a study conducted in China, 255 (25.4\%) were stx-positive using PCR. A total of 93 STEC isolates were obtained from 62 samples, giving a culture positive rate of $6.2 \%(62 / 1003)$, and all of isolates harboured the $s t x_{2 e}$ subtype (Meng et al., 2014). The prevalence of STEC was also investigated in 720 faecal samples randomly collected from a commercial breeding farm in China during a one-year surveillance period. Eight strains (1.1\%) of sorbitol-negative STEC 0157 and 33 strains (4.6\%) of STEC non-0157 were isolated (Yan et al., 2011). In a study performed in Hong Kong, stx-positive strains were isolated from $5.1 \%$ of 487 swine faecal samples, but only $2.1 \%$ (10/487) were confirmed as Shiga-toxin producing using the Vero-cell assay. The 0157:H7 serotype was not isolated and the predominant genotype was $s t x_{2 e}$-positive, eaeA-negative and $h l y A$-negative (Leung et al., 2001). STEC strains were also isolated from pigs in India. A total of 782 rectal swabs were collected from clinically healthy and diarrhoeic piglets. STEC strains were detected in 113 (14.4\%) samples: STEC 0157 was isolated from four piglets (0.5\%) and non-0157 STEC was isolated from 109 (13.9\%) animals (Rajkhowa and Sarma, 2014).

Pigs as potential reservoirs for STEC have also been reported in Africa. In a South Africa study, three STEC strains (1.1\%) were isolated from 263 swine faecal samples. All of the strains harboured $s t x_{2 e}$ subtype (Mohlatlole $e t$ al., 2013). Another study investigated the presence of seven potentially pathogenic STEC serogroups (0157, 026, 091, 0103, 011, 0128 and 0145 ) in the faeces of 409 pigs in Ibadan, Nigeria. STEC strains were found in 23 faecal samples (5.7\%): 20 isolates (4.9\%) belonged to 0157 serogroup, one $(0.3 \%)$ to 026 serogroup, and two (0.5\%) to 0111 (0jo et al., 2010).

These studies show that the incidence of STEC in swine populations varied in multiple regions of the world. The observed differences could be due to variances in husbandry practices and prevailing climatic conditions of the geographical area being studied (Rajkhowa and Sarma, 2014). The variation in methods used for the detection and isolation of STEC may be a factor contributing to differences among prevalence measurements (Fratamico et al., 2004).

Similarly, several studies conducted in European countries reported wide-ranging estimates of STEC prevalence from swine car- casses and pork products. In Belgium, five pig carcasses (12.8\%) from 132 examined were stx-positive in PCR (Bottledoorn et al., 2002). A study conducted in Italy showed that, of the 150 carcasses examined by using immunomagnetic separation (IMS) techniques, only one $(0.7 \%)$ was contaminated by STEC 0157 (Bonardi et al., 2003). In France, the swine carcass STEC contamination rate, detected using molecular methods, varied from $12 \%$ to $50 \%$ (Bouvet et al., 2001, 2002a). The highest prevalence was reported in 150 pig carcasses. For each carcass, eight sites were sampled using destructive methods. A total of 1200 specimens were analysed with PCR and a high percentage $(50 \%, 75 / 150)$ of $s t x$-positive samples was found (Bouvet et al., 2001). A later study analysed the effects of slaughter processes on pig carcass STEC contamination. In this study, 182 carcasses were sampled at different steps of the slaughter process. The contamination rates were $46 \%$ (83/182) after bleeding, $16 \%$ (29/182) after dressing and 15\% (28/182) after chilling using PCR analysis. Moreover, environmental samples were collected in different sites of the slaughterhouses at different times during the workday. Global carcass contamination decreased with the slaughter process, whereas environmental contamination increased. These results show that regular cleaning-disinfecting during the slaughter process could avoid, or at least decrease, the risk of STEC cross-contamination of carcasses (Bouvet et al., 2002b). Another French study evaluated the effects of the cutting process on pork meat STEC contamination. In total, 525 pig carcass samples were collected, as well as 525 untrimmed cut samples and 550 rindlessboneless cuts. Contamination rates were $12 \%$ (61/525), $19 \%(99 / 525)$ and 5\% (28/559) respectively, showing a significant increase of STEC contamination, in particular, during the primary cutting process. Among the pork samples tested, none gave a positive result with PCR for E. coli 0157:H7 (Bouvet et al., 2002a). Some other European studies reported STEC presence in pork products. An Italian study analysed 126 fresh pork sausages for the presence of STEC using PCR and isolation methods. Out of 126 samples screened using PCR 20 (15.9\%) were positive for $s t x$ genes. In particular, $50 \%$ of the $s t x$-positive pork specimens (10/20) were contaminated with 0157:H7 E. coli, giving positive results for the $r f b E_{0157: \mathrm{H} 7}$ gene. Moreover, 24 stx-positive strains were isolated from $13 s t x$-positive samples (10.3\%, 13/126) and 15 were shown to have the 0157 serotype (Villani et al., 2005). Another Italian study, conducted by Bardasi et al., (2015) reported data from a two-year STEC monitoring plan carried out in the Emilia Romagna Region. A total of 689 meat samples from different species were collected and analysed according to ISO/TS 13136, including 213 pork 
samples. STEC virulence genes were detected in 41 out of 213 (19\%) fresh sausages from pork meat and one STEC strain of E. coli 0103 eae and stx1-positive was isolated (Bardasi et $a l ., 2015)$. In UK, testing of pork sausages by DNA hybridisation showed the presence of STEC in 46 (25\%) of 184 samples (Smith et al., 1991). In Austria, from 120 pork meat samples, two (1.7\%) Shiga toxin-producing $E$. coli strains were isolated (Mayrhofer et al., 2004).

A wide range of values has also been reported from pork products and carcass samples collected in many countries. In the USA, STEC detection by DNA hybridisation in pork meat was reported in $18 \%(9 / 51)$ of 51 samples collected from Seattle area grocery stores (Samadpour et al., 1994). More recently, a study was published in which 231 ground pork samples were collected in the Washington D.C. area. Among the 231 samples, 31 (13.4\%) were positive for the stx gene using PCR screening. Positive specimens were further analysed using colony hybridisation, and STEC was isolated from 13 (5.2\%) of the pork samples. All of the STEC isolates were negative for 0157 serogroups (Ju et al., 2012). In Canada, Read et al. (1990) examined the prevalence of STEC in 235 ground pork samples. Based on the neutralisation of cytotoxic activity in the Vero-cell assay, the prevalence of STEC was $10.6 \%$ (25/235). Isolations of STEC were obtained from nine $(3.8 \%)$ of the pork samples. Positive results were obtained for 51 (4.8\%) of 1067 carcasses tested using PCR for stx genes (bohaychuk et al., 2011) Borges et al. (2012) examined the presence of STEC in 215 swine carcasses using PCR and isolation techniques in Brazil. Shiga-toxin encoding genes were detected in 12 samples (5.6\%), and the prevalence of STEC isolates was $0.4 \%$ (1/215). The STEC isolate identified in this study was positive for $s t x_{2 e}$ and did not belong to the 0157:H7 serotype. In Asia, Leung et al. (2001) tested 487 pig carcass samples collected in an abattoir in Hong Kong. Strains positive for stx, using PCR, were obtained from $2.3 \%$ of samples and they were also tested with a Vero-cell cytotoxicity assay. Shiga toxin-producing $E$. coli was isolated from only one pig carcass. In an African study, the presence of seven potentially pathogenic STEC serogroups (0157, 026, 091, 0103, 011, 0128 and 0145) was investigated in 200 pork samples collected in Nigeria. STEC strains were found in eight samples (4\%), with six isolates belonging to the 0157 serogroup (3\%, 6/200) (Ojo et al., 2010).

Although human disease associated with swine STEC is uncommon, outbreaks and cases of illness due to different STEC serotypes have occurred worldwide (Fratamico et al., 2004). Pork products have only been reported as a vehicle involved in outbreaks of STEC 0157 infections in a few instances. In Ontario, Canada, an outbreak of Escherichia coli $0157:$ H7 occurred in 1998. Genoa salami, made with pork and beef, was identified as the most probable source of the outbreak (Williams et al., 2000). Similarly, in 1999, an outbreak of STEC 0157:H7 infections was identified in British Columbia. The case-control study found that the infection was significantly associated with salami consumption. This product was obtained from raw pork, but also from raw beef (MacDonald et al., 2004). Pork was also implicated in a STEC 0157:H7 outbreak in Ontario in 2011. Pork from a pig roast was identified as the most probable source of the STEC infection (Troz-Williams et al., 2012). In Italy in 2004, a family outbreak of STEC 0157 infection was reported, associated with the consumption of dry-fermented salami made with pork meat only and produced in a local plant. E. coli 0157 non-motile strains were isolated from the patients that were hospitalised with bloody diarrhoea carried stxl, stx2 and eae genes (Conedera et al., 2007). In Australia, a locally produced dry fermented sausage, made with a mixture of raw pork, beef and lamb, was identified as the source of an outbreak of HUS in 1995. STEC isolates belonged to the serotype 0111:H- and harboured stx 1 and stx2 genes (Paton et al., 1996). Although there are few reports of STEC outbreaks implicating pork as the likely source of infection, the results of these investigations emphasise the importance of considering other meat products besides beef as potential vehicle of STEC transmission (Troz-Williams et al., 2012; Tseng et al., 2014a).

\section{Differences between human and swine Shiga toxin-produc- ing Escherichia coli strains}

Although pigs are a potential reservoir for STEC strains, different genetic profiles are described in STEC of swine origin and human origin (Sonntag et al., 2005). Typical swinepathogenic $E$. coli strains include oedema disease and post-weaning diarrhoea-causing $E$. coli, which generally express haemolysin (encoded by hly gene), F18 fimbrial adhesin (encoded by fedA gene), adhesin involved in diffuse adherence (AIDA), F4 fimbriae (K88) and Shiga-like toxin 2e. Porcine pathogenic $E$. coli strains usually belong to a limited number of serogroups (08, 0108, 0138, 0139, 0141, 0147 and 0149), which differ from those commonly associated with $s t x_{2 e}$-positive human isolates (Sonntag et al., 2005; Schierack et al., 2006). Interestingly, st $x_{2 e}$-producing STEC belonging to serogroup 0101, reported in human cases, has been isolated from slaughtered pigs, suggesting that pigs could be the natural reservoir of 0101 strains (Caprioli $e t$ al., 1993).

In contrast to Stxl and Stx2, which are encoded in the genome of temperate bacteriophages, the $s t x_{2 e}$ gene in STEC associated with oedema disease has been reported to be located in the chromosome, because no Stx-converting phages could be isolated from such strains (Muniesa et al., 2000). Stx $_{2 \mathrm{e}}$-producing strains are also isolated from food, the environment and, albeit rarely, from humans. A lambdoid phage, called P27, carrying an $s t x_{2 e}$ gene, was isolated from a human STEC strain, but inducible stx-carrying phages were not found in other types of st $_{2 \mathrm{e}}$-producing strains from different origins (Muniesa et al., 2000; Beutin et al., 2008). Nevertheless, only in a few cases have $s t x_{2 e}$-positive strains been detected from humans, accounting for only 0.9 to $1.7 \%$ of human STEC isolates (Sonntag et al., 2005; Beutin et al., 2008). Stx $\mathrm{x}_{2 \mathrm{e}}$-producing STEC has especially been found in patients showing mild diarrhoea or in asymptomatic carriers. However, severe clinical symptoms, such as HUS, are described (Thomas et al., 1994; Fasel et al., 2014). In these human cases, no particular source of infection has been identified (Tseng et al., 2014a).

Additionally, st $_{2 \mathrm{e}}$ differs from other Shigatoxins by having particular receptor specificity. The B-subunits of Shiga-like toxins generally recognise cell surface glycolipid globotriaosylceramide (Gb3), and to a lesser extent, globotetraosyceramide (Gb4) as receptors (Karve and Weiss 2014). In the pathogenesis of pig oedema disease, stx $\mathrm{x}_{\mathrm{e}}$ enters the bloodstream and binds prevailingly to the receptor $\mathrm{Gb} 4$, which is located on the epithelial and endothelial cells. The toxin-induced blood vessel damage causes oedema, ataxia and death in swine (Tseng et al., 2014a). The finding that high-st $x_{2 \mathrm{e}}$-producing strains are isolated from humans with no or only mild enteric symptoms suggests a lack of Gb4 and Gb3 receptors in human enterocytes (Beutin et al., 2008).

Moreover, Sonntag et al. (2005) found that all of the 13 st $x_{2 e}$-containing strains isolated from 11,056 human stools adhered to human intestinal epithelial cell lines T84 and HCT-8, but not to pig intestinal epithelial cell line IPEC-J2. In contrast, most of the $s t x_{2 e}$ - harbouring $E$. coli isolated from piglets with oedema disease and post-weaning diarrhoea completely lysed human intestinal epithelial cells and adhered to IPEC-J2 cells. In the analysis of genetic profiles, stx $_{2 \mathrm{e}}$-producing strains isolated from humans lack swine virulence factors, such as AIDA and F18 adhesins, and do not belong to serogroups 0138, 0139 and 0141. These data indicate that $s \mathrm{x}_{2 \mathrm{e}}$-producing STEC strains show host-specific patterns of interaction with intestinal epithelial cells and specific virulence factors, which allow them to adapt to the hosts and cause various forms of disease. 


\section{Molecular and microbiological methods for Shiga toxin-pro- ducing Escherichia coli detec- tion in the swine production chain}

The STEC pathogroup comprises over 400 serotypes that differ greatly in both their pathogenic profile and their phenotypic characteristics. This diversity is reflected in the application of a wide range of detection methods in scientific studies, monitoring programmes, official food controls and human analysis laboratories (Holland et al., 2000; Farrokh et al., 2013). ISO 16654:2001 describes a microbiological method for the detection of Escherichia coli 0157 in food and animal feeding stuffs, based on IMS (ISO, 2001). In 2012, ISO approved a real-time PCR-based method (ISO/TS 13136:2012) for the detection of STEC and the determination of 0157, 0111, 026, 0103 and 0145 serogroups in food, animal feed and environmental samples in the areas of food production and primary production. The ISO 13136 method is comprised of these sequential steps: microbial enrichment, nucleic acid extraction, real-time PCR for the detection of virulence genes (stx1, stx2 and eventually eae), detection of top-five serogroup-associated genes in stx and eae-positive samples, STEC isolation and molecular confirmation of isolates (ISO, 2012).

An enrichment step is used with the aim of resuscitating stressed target cells, increasing the target cell number, and diluting the effects of matrix inhibitors and background flora on the assay (Wang et al., 2013). Rantsiou et al. (2011) compared quantitative PCR (qPCR) protocols applied directly to food samples (including fresh and dry-fermented pork meat) and after a non-selective enrichment $\left(37^{\circ} \mathrm{C}\right.$ for $24 \mathrm{~h}$ in Brain Heart Infusion broth); the number of $s t x$-positive samples did not vary significantly between the two sampling points. Application of qPCR without enrichment allowed for a shortened analysis time and the quantification of real STEC contamination levels in food specimens. Nevertheless, the signal obtained in the direct qPCR could be originated from DNA of dead bacterial cells. After an enrichment step, the signal is necessarily associated with multiplying populations. Moreover, for STEC contamination levels below the qPCR assay detection limit, an enrichment step was deemed necessary (Rantsiou et al., 2011).

In ISO 13136, the enrichment medium is chosen as a function of the sample types. In particular, modified tryptone-soy broth supplemented with novobiocin $(\mathrm{m}-\mathrm{TSB}+\mathrm{N})$ is replaced by buffered peptone water (BPW) to analyse samples that are assumed to contain stressed target bacterial cells and low levels of contaminating microflora (such as frozen products). The addition of novobiocin is controversial and several authors have investigated it (ISO, 2012). Although novobiocin is commonly added to m-TSB at concentrations of 20 $\mathrm{mg} / \mathrm{L}$ to enrich STEC 0157, as specified in ISO 16654 , this antibiotic can inhibit the growth of some non-0157 STEC strains, and therefore ISO 13136 specified a lower concentration (16 $\mathrm{mg} / \mathrm{L}$ ), as indicated by Vimont et al. (2007). The authors analysed a minimum inhibitory concentration (MIC) of 74 E. coli $0157: \mathrm{H} 7$ and 55 non-0157:H7 STEC strains to novobiocin. The MIC values varied from 32 to $>64 \mathrm{mg} / \mathrm{L}$ for the 74 E. coli $0157: \mathrm{H7}$ strains, and from 16 to $>64 \mathrm{mg} / \mathrm{L}$ for the 55 non-0157:H7 STEC strains, showing that the addition of novobiocin into enrichment broths can slow or inhibit the growth of some STEC strains. Kanki et al. (2011) noted that non-novobiocincontaining m-TSB enrichment medium exhibited superior ability to facilitate the detection of low numbers of non-0157 STEC cells in pure culture and food samples.

For the molecular analysis of STEC virulence genes in accordance with ISO 13136 norm, the nucleic acid extraction technique depends on the requirements of the adopted detection system (ISO, 2012). The ideal DNA extraction protocol would provide the highest yield of DNA with minimal coextraction of potential inhibitors, coupled with a simple and rapid procedure (Holland et al., 2000). Although DNA-based methods, such as PCR, are highly specific, reproducible, sensitive and characterised by high discriminatory power, they are strongly limited by the presence of inhibitors in the different samples. In particular, PCR inhibitors, such as polysaccharides and humic acids, are abundant in several types of food. The DNA extraction procedure, based on the use of silica-column systems, demonstrated high efficiency in DNA-binding and removing inhibitors with complex and processed food matrices (Di Pinto et al., 2007). DNA extraction from faeces is challenging due to the presence of Taq polymerase inhibitors, which include heme, bilirubin, bile salts and complex carbohydrates and the nonuniformity of samples in terms of physical matter, target organisms and background flora. False-negative PCR results may be due to inhibitors, or to the presence of a small number of target organisms in the volume of faeces sampled or to the decreased stability of cells with storage (Holland et al., 2000). Although direct extracts of faeces can be used as a template for PCR, sensitivity has often been suboptimal because of the presence of Taq polymerase inhibitors. For this reason, Paton et al. strongly recommended that faecal specimens be first cultured in a suitable enrichment medium (Paton and Paton, 2003). Commercial kits that involve spin columns have been considered as suitable methods for the DNA extraction of STEC from human stool samples, as well as from animal faecal specimens (Holland et al., 2000; Gioffré et al., 2004).

Molecular methods based on the recognition of virulence genes and serogroups are increasingly used to characterise and delineate STEC from other forms of $E$. coli (Franz et al., 2014). Since the early 1990s, numerous PCR assays have been developed to detect stx1 and stx2. Although most PCR assays were fast and sensitive, performances varied when evaluated independently. With the advent of real-time PCR technology in the 2000s, great improvements were made in the speed and sensitivity of STEC detection. In addition, many PCR assays were developed for the detection of other virulence factors and STEC serogroups (Wang et al., 2013). Besides the possible presence of assay inhibitors in the sample matrix, another caveat associated with PCR-based screening is the inability to differentiate dead from viable cells. The inclusion of internal amplification controls and the addition of viability dyes, such as propidium monoazide, have been developed to address those concerns. Moreover, the detection of virulence genes is not a guarantee of phenotypic gene expression and, in the case of multiple STEC strains contaminating a single sample, further confirmation is needed to determine whether the gene profiles detected belong to a single strain or to multiple different strains. The isolation of the strains is necessary to confirm that the positive PCR signals are generated from genes present in the same live STEC cell (Wang et al., 2013).

Several studies have revealed the difficulty of obtaining STEC isolates from stx-positive enrichment cultures (Grant et al., 2009). Although differential media have been developed to facilitate the isolation of $E$. coli 0157:H7, these media are not generally effective for many STEC strains because of multiple reaction colours, due to sorbitol fermentation and $\beta$-D-glucuronidase activity. Also, several selective agar media, such as those containing novobiocin and tellurite, are enabled to support the growth of a significant portion of non0157:H7 strains (Gill et al., 2014). Failure to isolate STEC from stx-positive samples may also be due to the loss of Stx prophages during subculturing, the presence of other bacteriacarrying stx, the presence of stx-carrying phages, bacterial cells in a viable but non-culturable (VBNC) state, high levels of background microflora, or low levels of target bacteria in the sample (Ju et al., 2012; Farrokh et al., 2013; Meng et al., 2014). ISO 13136 indicates that a serogroup-specific enrichment may be used to facilitate the isolation of STEC (ISO, 2012). Commercial immunomagnetic separation assays are available for the selective con- 
centration of the 0157 serogroup and for a subset of few non-0157 serogroups most frequently involved in HUS outbreaks. The detection of this non-0157 STEC by IMS is subject to serogroup-specific variations in capture efficiency (Farrokh et al., 2013). Colony-lift hybridisation procedures have also been applied in an effort to increase the isolation of non-0157 STEC strains when they are present at low levels relative to background microflora. The samples are plated out and hybridised onto membranes with $s t x$-labelled probes to facilitate the isolation of non-0157 STEC (Wang et al., 2013). However, many challenges related to non-0157 STEC detection still remain, since these are comprised of a heterogeneous group of pathogens with different phenotypic features (Smith et al., 2014).

Currently, the rapidly evolving next generation of sequencing technologies are an emerging powerful tool that may potentially transform the methods used for identifying and characterising Shiga toxin-producing $E$. coli (Wang et al., 2013). The continuing reduction in sequencing costs and the shortening of the time-to-result makes the whole genome sequencing an attractive strategy for improving different aspects of public health. This technology will increasingly influence diagnostics, risk management, epidemiology and research in the field of food safety (Franz et al., 2014).

\section{Discussion}

Although pigs are not generally considered relevant STEC reservoirs given the low known incidence of cases of severe human illness associated with STEC of swine origin, the role of swine in STEC epidemiology needs to be further investigated (Tseng et al., 2014a). The interaction of bacteriophages, the acquisition of pathogenicity islands, and horizontal gene transfer make the STEC genome highly flexible and dynamic (Franz et al., 2014). Phagemediated transduction of virulence genes can generate highly virulent pathotypes (Imamovic et al., 2010). Moreover, Stx phages are extremely persistent in the environment and pig wastewater shows higher densities of Stx phages than do cattle and poultry wastewater and urban sewage (Imamovic et al., 2010). Because many of STEC virulence genes are located on mobile elements, the evolution of new STEC variants and the emergence of different sources of human infection cannot be neglected (Franz et al., 2014). Recently, the European Shiga toxin-producing enteroaggregative Escherichia coli 0104:H4 outbreak associated with fenugreek sprouts in 2011 provided a clear example of the importance of mobile elements in the acquisition of unusual virulence profiles and highlighted the pathogenic role of non-0157 STEC strains (Krüger and Lucchesi, 2015). The emergence of non0157 STEC serotypes has become a serious challenge for both the agri-food sector operators and public health authorities (Franz et al., 2014). The severity of human illness and high mortality rate associated with STEC infection justify the growing attention of public health authorities to STEC and the inclusion of this group of bacteria as an important foodborne pathogen. However, the current monitoring activities performed as part of the Zoonoses Directive (2003/99/EC), although providing valuable data for individual Member States, lack harmonisation in places (EFSA, 2007). The number of samples collected and types of food sampled varied among individual MS (EFSA and ECDC, 2015). Application of monitoring programmes, good hygiene practices and efficient validated HACCP-procedures in the whole food production chain is an important instrument to control the public health risks associated with STEC infection (EFSA, 2007). The prevention and control of foodborne diseases caused by STEC also require continuous improvement of analytical tools to understand the virulence, origins, and epidemiology of these bacteria, in order to devise strategies that lessen the risk of foodstuff contamination and eventually anticipate the emergence and the spreading of new forms of these pathogens (Franz et al., 2014). Further investigations about the association between swine STEC and human illness can elucidate the epidemiology of STEC, particularly non-0157 serotypes (Tseng et al., 2014a).

Furthermore, the study of STEC mechanisms of action applied to animal models is a useful tool to understand the pathogenesis of human disease and develop new therapies. Because swine oedema disease shares many pathogenic similarities to HUS, including localised production of toxins in the gut, toxin translocation across intestinal epithelium and dissemination to target organs via the bloodstream, porcine models have been used in scientific studies for the development of novel post-exposure therapies for HUS in human beings, such as Stx receptor mimic probiotics, which should bind and neutralise Shiga-like toxins within the intestinal lumen (Hostetter et al., 2014).

\section{Conclusions}

Among the other practical implications related to the study of these bacteria, studies about the interactions between Shiga-like toxins and cell-surface-exposed glycosphingolipids suggest attractive perspectives in the field of oncology. Aberrant enhanced expres- sions of the Stx-receptor Gb3Cer/CD77 have been reported with various human solid tumours and have also been correlated with the development of metastasis in colon cancer. These data suggest the possible development, in the future, of targeted therapies based on Stx or Stx-derived constructs for patients with unresectable tumours or advanced cancer refractory to chemotherapy (Distler et al. 2009).

\section{References}

Bardasi L, Taddei R, Nocera L, Ricchi M, Merialdi G, 2015. Shiga-toxin-producing Escherichia coli in meat and vegetable products in Emilia Romagna Region, years 20122015. Ital J Food Safety 4:33-5.

Bergan J, Lingelem A, Simm R, Skotland T, 2012. Shiga toxins. Toxicon 60:1085-107.

Beutin L, Geier D, Steinrück H, Zimmermann S, Scheutz F, 1993. Prevalence and some properties of verotoxin (Shiga-like toxin)-producing Escherichia coli in seven different species of healthy domestic animals. J Clin Microbiol 31:2483-8.

Beutin L, Krüger U, Krause G, Miko A, Martin A, Strauch E, 2008. Evaluation of major types of Shiga toxin 2e-producing Escherichia coli bacteria present in food, pigs, and the environment as potential pathogens for humans. Appl Environ Microb 74:4806-16.

Bohaychuk VM, Gensler GE, Barrios PR, 2011. Microbiological baseline study of beef and pork carcasses from provincially inspected abattoirs in Alberta, Canada. Can Vet $\mathrm{J}$ 52:1095:100.

Bolton JD, 2011. Verocytotoxigenic (Shiga toxinproducing) Escherichia coli: virulence factors and pathogenicity in the farm to fork paradigm. Foodborne Pathog Dis 8:357-65.

Bonardi S, Brindani F, Pizzin G, Lucidi L, D'Incau M, Liebana E, Morabito S, 2003. Detection of Salmonella spp, Yersinia enterocolitica and verocytotoxin-producing Escherichia coli 0157 in pigs at slaughter in Italy. Int J Food Microbiol 85:101-10.

Borges CA, Beraldo LG, Maluta RP, Cardozo MV, Guth BE, Rigobelo EC, de Ávila FA, 2012. Shiga toxigenic and atypical enteropathogenic Escherichia coli in the feces and carcasses of slaughtered pigs. Foodborne Pathog Dis 9:1119-25.

Borie C, Monreal Z, Guerrero P, Sanchez ML, Martinez J, Arellano C, Prado V, 1997. Prevalence and characterization of enterohaemorrhagic Escherichia coli isolated from healthy cattle and pigs slaughtered in Santiago, Chile. Arch Med Vet 29:205-12.

Botteldoorn N, Heyndrickx M, Rijpens N, Herman L, 2002. Detection and characterization of verotoxigenic Escherichia coli by a 
VTEC/EHEC multiplex PCR in porcine faeces and pig carcass swabs. Res Microbiol 154:97-104.

Bouvet J, Bavai C, Rossel R, Le Roux A, Montet MP, Ray-Gueniot S, Mazuy C, Arquillière C, Vernozy-Rozand C, 2001. Prevalence of verotoxin-producing Escherichia coli and E. coli 0157:H7 in pig carcasses from three French slaughterhouses. Int $\mathrm{J}$ Food Microbiol 71:249-55.

Bouvet J, Bavai C, Rossel R, Le Roux A, Montet MP, Ray-Gueniot S, Mazuy C, Atrache V, Vernozy-Rozand C, 2002a. Effects of cutting process on pork meat contamination by verotoxin-producing Escherichia coli (VTEC) and E. coli 0157:H7. Int J Food Microbiol 77:91-7.

Bouvet J, Montet MP, Rossel R, Le Roux A, Bavai C, Ray-Gueniot S, Mazuy C, Atrache V, Vernozy-Rozand C, 2002b. Effects of slaughter processes on pig carcass contamination by verotoxin-producing Escherichia coli and E. coli 0157:H7. Int J Food Microbiol 77:99108.

Caprioli A, Morabito S, Brugère H, Oswald E. Enterohaemorragic Escherichia coli: emerging issues on virulence and modes of transmission. Vet Res 2005;36:289-311.

Caprioli A, Nigrelli A, Gatti R, Zavanella M, Blando AM, Minelli F, Donelli G, 1993. Characterization of verocytotoxin-producing Escherichia coli isolated from pigs and cattle in northern Italy. Vet Rec 133:323-4.

Conedera G, Mattiazzi E, Russo F, Chiesa E, Scorzato I, Grandesso S, Bessegato A, Fioravanti A, Caprioli A, 2007. A family outbreak of Escherichia coli 0157 haemorrhagic colitis caused by pork meat salami. Epidemiol Infect 135:311-4.

Di Pinto A, Forte VT, Corsignano Guastadisegni M, Martino C, Schena FP, Tantillo G, 2007. A comparison of DNA extraction methods for food analysis. Food Control 18:76-80.

Distler U, Souady J, Hülsewing M, Drmi Hofman I, Haier J, Friedric AW, Karch H, Senningger N, Dreisewerd K, Berkenkamp S, Schmidt MA, Peter-Katalini J, Müthing J, 2009. Shiga toxin receptor Gb3Cer/CD77: tumor-association and promising therapeutic target in pancreas and colon cancer. PloS One 4:e6813.

EFSA, 2007. Scientific opinion on monitoring of verotoxigenic Escherichia coli (VTEC) and identification of human pathogenic VTEC types. EFSA J 579:1-61.

EFSA and ECDC, 2015. The European Union summary report on trends and sources of zoonoses, zoonotic agents and food-borne outbreaks in 2013. EFSA J 13:3991.

Eriksson E, Nerbrink E, Borch E, Aspan A, Gunnarsson A, 2003. Verocytotoxin-producing Escherichia coli 0157:H7 in the Swedish pig population. Vet Rec 152:712-7.

European Commission, 2003. Directive of the
European Parliament and of the Council of 17 November 2003 on the monitoring of zoonoses and zoonotic agents, amending Council Decision 90/424/EEC and repealing Council Directive 92/117/EEC, 2003/99/EC. In: Official Journal, L 325, 12.12.2003, pp 3140.

Farrokh C, Jordan K, Auvray F, Glass K, Oppegaard H, Raynaud S, Thevenot D, Condron R, De Reu K, Govaris A, Heggum K, Heyndickx M, Hummerjohann J, Lindsay D, Miszczycha S, Moussiegt S, Verstraete K, Cerf 0, 2013. Review of Shiga-toxin-producing Escherichia coli (STEC) and their significance in dairy production. Int $\mathrm{J}$ Food Microbiol 162:190-212.

Fasel D, Mellmann A, Cernela N, Hächler H, Fruth A, Khanna N, Egli A, Beckmann C, Hirsch HH, Goldenberg D, Stephard R, 2014. Hemolytic uremic syndrome in a 65 -year-old male linked to a very unusual type of stx2eand eae-haboring 051:H49 Shiga toxin-producing Escherichia coli. J Clin Microbiol 52:1301-3.

Feder I, Wallace FM, Gray JT, Fratamico PM, Fedorka-Cray J, Pearce RA, Call JE, Perrine $\mathrm{R}$, Luchansky JB, 2003. Isolation of Escherichia coli 0157:H7 from intact colon fecal samples of swine. Emerg Infect Dis 9:380-3.

Frank C, Weber D, Cramer JP, Askar M, Faber M, der Heiden M, Bernard H, Fruth A, Prager R, Spode A, Wadl M, Zoufaly A, Jordan S, Kemper MJ, Follin P, Müller L, King L, Rosner B, Buchholz U, Stark K, Krause G, 2011. Epidemic profile of Shiga-toxin-producing Escherichia coli 0104:H4 outbreak in Germany. New Engl J Med 365:1771-80.

Franz E, Delaquis P, Morabito S, Beutin L, Gobius K, Rasko DA, Bono J, French N, Osek J, Lindstedt BA, Muniesa M, Manning S, LeJeune J, Callway T, Beatson S, Eppinger M, Dallman T, Forbes KJ, Aarts H, Pearl DL, Gannon VPJ, Laing CR, Strachn NJC, 2014. Exploiting the explosion of information associated with whole genome sequencing to tackle Shiga toxin-producing Escherichia coli (STEC) in global food production systems. Int J Food Microbiol 187:57-72.

Fratamico PM, Bagi LK, Bush EJ, Solow BT, 2004. Prevalence and characterization of shiga toxin-producing Escherichia coli in swine feces recovered in the National Animal Health Monitoring System's swine 2000 study. Appl Environ Microb 70:7173-8.

Friesema I, van der Zwaluw K, Schuurman T, Kooistra-Smid M, Franz E, van Duynhoven Y, van Pelt W, 2014. Emergence of Escherichia coli encoding Shiga toxin $2 \mathrm{f}$ in human Shiga toxin-producing E. coli (STEC) infections in the Netherlands, January 2008 to December 2011. Available from: http://www.eurosurveillance.org /images/dynamic/EE/V19N17/art20787.pdf
Gill A, Huszczynski G, Gauthier M, Blais B, 2014. Evaluation of eight agar media for the isolation of Shiga-toxin producing Escherichia coli. J Microbiol Meth 96:6-11.

Gioffré $\mathrm{A}$, Meichtri L, Zumàrraga $\mathrm{M}$, Rodrìguez R, Cataldi A, 2004. Evaluation of QIAamp DNA stool purification kit for Shiga-toxigenic Escherichia coli detection in bovine fecal swabs by PCR. Rev Argent Microbiol $36: 1-5$.

Grant M, Mogler MA, Harris DL, 2009. Comparison of enrichment procedures for Shiga toxin-producing Escherichia coli in wastes from commercial swine farms. J Food Protect 72:1982-6.

Gyles CL, 2007. Shiga toxin-producing Escherichia coli: an overview. J Anim Sci 85:45-62.

Heuvelink AE, Zwartkruis- Nahuis JTM, van den Biggelaar FLAM, van Leeuwen WJ, de Boer $\mathrm{E}$, 1999. Isolation and characterization of verocytotoxin-producing Escherichia coli 0157 from slaughter pigs and poultry. Int $\mathbf{J}$ Food Microbiol 52:67-75.

Holland JL, Louie L, Simor AE, Louie M, 2000. PCR detection of Escherichia coli 0157:H7 directly from stools: evaluation of commercial extraction methods for purifying fecal DNA. J Clin Microbiol 38:4108-13.

Hostetter SJ, Helgerson A, Paton JC, Paton AW, Cornick N, 2014. Therapeutic use of a receptor mimic probiotic reduces intestinal Shiga toxin levels in a piglet model of hemolytic uremic syndrome. BMC Res Notes 7:331.

Imamovic L, Ballesté E, Jofre J, Muniesa M, 2010. Quantification of Shiga toxin-converting bacteriophages in wastewater and fecal samples by real-time quantitative PCR. Appl Environ Microb 76:5693-701.

ISO, 2001. Microbiology of food and animal feeding stuffs. Horizontal method for the detection of Escherichia coli 0157. ISO Norm 16654:2001(E). International Organization for Standardization, Geneva, Switzerland.

ISO, 2012. Microbiology of food and animal feedReal-time polymerase chain reaction (PCR)-based method for the detection of food-borne pathogens-Horizontal method for the detection of Shiga toxin-producing Escherichia coli (STEC) and the determination of 0157, 0111, 026, 0103 and 0145 serogroups. ISO/TS Norm 13136:2012(E). International Organization for Standardization, Geneva, Switzerland.

Ju W, Shen J, Li Y, Toro MA, Zhao S, Ayers S, Najjar MB, Meng J, 2012. Non-0157 Shiga toxin-producing Escherichia coli in retail ground beef and pork in the Washington D.C. area. Food Microbiol 32:371-7.

Kanki M, Seto K, Harada T, Yonogi T, Kumeda Y, 2011. Comparison of four enrichment broths for the detection of non-0157 Shigatoxin-producing Escherichia coli 091, 0103, 0111, 0119, 0121, 0145 and 0165 from 
pure culture and food samples. Lett Appl Microbiol 53:167-73.

Karmali MA, Mascarenhas M, Shen S, Ziebell K, Johnson S, Reid-Smith R, Isaac-Renton J, Clark C, Rahn K, Kaper JB, 2003. Association of genomic 0 island 122 of Escherichia coli EDL 933 with verocytotoxin-producing Escherichia coli seropathotypes that are linked to epidemic and/or serious disease. J Clin Microbiol 41:493040.

Karve SS, Weiss AA, 2014. Glycolipid binding preferences of Shiga toxins variants. PloS One 9:e101173.

Kaufmann M, Zweifel C, Blanco M, Blanco JE, Blanco J, Beutin L, Stephan R, 2006. Escherichia coli 0157 and non-0157 Shiga toxin-producing Escherichia coli in fecal samples of finished pigs at slaughter in Switzerland. J Food Protect 69:260-6.

Kijima-Tanaka M, Ishihara K, Kojima A, Morioka A, Nagata R, Kawanishi M, Nakazawa M, Tamura Y, Takahashi T, 2005. A national surveillance of Shiga toxin-producing Escherichia coli in food-producing animals in Japan. J Vet Med B 52:230-7.

Krüger A, Lucchesi PMA, 2015. Shiga toxins and stx phages: highly diverse entities. Microbiology 161:451-62.

Leung PHM, Yam WC, Ng WWS, Peiris JSM, 2001. The prevalence and characterization of verotoxin-producing Escherichia coli isolated from cattle and pigs in an abattoir in Hong Kong. Epidemiol Infect 126:173-9.

MacDonald DM, Fyfe M, Paccagnella A, Trinidad A, Louie K, Patrick D, 2004. Escherichia coli 0157:H7 outbreak linked to salami, British Columbia, Canada, 1999. Epidemiol Infect 132:283-9.

Martins PR, da Silva MC, Dutra V, Nakazato L, da Silva Leite D, 2011. Prevalence of enterotoxigenic and Shiga toxin-producing Escherichia coli in pigs slaughtered in Mato Grosso, Brazil. J Infect Dev Ctries 5:123-6.

Mayrhofer S, Paulsen P, Smulders FJM, Hilbert F, 2004. Antimicrobial resistance profile of five major food-borne pathogens isolated from beef, pork and poultry. Int J Food Microbiol 97:23-9.

Meng Q, Bai X, Zhao A, Lan R, Du H, Wang T, Shi C, Yuan X, Bai X, Ji S, Jin D, Yu B, Wang Y, Sun H, Liu K, Xu J, Xiong Y, 2014. Characterization of Shiga toxin-producing Escherichia coli from healthy pigs in China. BMC Microbiol 14:5.

Mohlatlole RP, Madoroba E, Muchadeyi FC, Chimonyo E, Kanengoni AT, Dzomba EF, 2013. Virulence profiles of enterotoxigenic, Shiga toxin and enteroaggregative Escherichia coli in South African pigs. Trop Anim Health Pro 45:1339-405.

Muniesa M, Recktenwald J, Bielaszewska M, Karch H, Schmidt H, 2000. Characterization of a Shiga toxin 2e-converting bacterio- phage from an Escherichia coli strain of human origin. Infect Immun 68:4850-5.

Ojo OE, Ajuwape ATP, Otesile EB, Owoade AA, Oyekunle MA, Adetosoye AI, 2010. Potentially zoonotic Shiga toxin-producing Escherichia coli serogroups in the faeces and meat of food-producing animals in Ibadan, Nigeria. Int $\mathrm{J}$ Food Microbiol 142:214-21.

Paton AW, Paton JC, 2003. Detection and characterization of STEC in stool samples using PCR. Methods Mol Med 73:45-54.

Paton AW, Ratcliff RM, Doyle RM, SeymourMurray J, Davos D, Lanser JA, Paton JC, 1996. Molecular microbiological investigation of an outbreak of hemolytic-uremic syndrome caused by dry fermented sausage contaminated with Shiga-like toxin-producing Escherichia coli. J Clin Microbiol 34:1622-7.

Rajkhowa S, Sarma DK, 2014. Prevalence and antimicrobial resistance of porcine 0157 and non-0157 Shiga toxin-producing Escherichia coli from India. Trop Anim Health Pro 46:931-7.

Rantsiou K, Mataragas M, Alessandria V, Cocolin L, 2011. Understanding the behaviour of foodborne pathogens in the food chain: new information for risk assessment analysis. Trends Food Sci Tech 22:21-9.

Read SC, Gyles CL, Clarke RC, Lior H, McEwen S, 1990. Prevalence of verocytotoxigenic Escherichia coli in ground beef, pork, and chicken in southwestern Ontario. Epidemiol Infect 105:11-20.

Samadpour M, Ongerth JE, Liston J, Tran N, Nguyen D, Whittam TS, Wilson RA, Tarr PI, 1994. Occurrence of Shiga-like toxin-producing Escherichia coli in retail fresh seafood, beef, lamb, pork, and poultry from grocery stores in Seattle, Washington. Appl Environ Microb 60:1038-40.

Scheutz F, Teel LD, Beutin L, Piérard D, Buvenz G, Karch H, Mellmann A, Caprioli A, Tozzoli A, Morabito S, Strockbine NA, Melton-Celsa AR, Sanchez M, Persson S, O'Brien AD, 2012. Multicenter evaluation of a sequencebased protocol for subtyping Shiga toxins and standardizing Stx nomenclature. J Clin Microbiol 50:2951-63.

Schierack P, Steinrück H, Kleta S, Vahjen W, 2006. Virulence factor gene profiles of Escherichia coli isolates from clinically healthy pigs. Appl Environ Microb 72:6680-6.

Schouten JM, van de Giessen AW, Frankena K, De Jong MCM, Graat EAM, 2005. Escherichia coli 0157 prevalence in Dutch poultry, pig finishing and veal herds and risk factors in Dutch veal herds. Prev Vet Med 70:1-15.

Smith HR, Cheasty T, Roberts D, Thomas A, Rowe B, 1991. Examination of retail chickens and sausages in Britain for Vero cytotoxin-producing Escherichia coli. Appl
Environ Microb 57:2091-3.

Smith JL, Fratamico PM, Gunther IV NW, 2014. Shiga toxin-producing Escherichia coli. Adv Appl Microbiol 86:145-97.

Sonntag AK, Bielaszwska M, Mellmann A, Dierksen N, Schierack P, Wieler LH, Schmidt MA, Karch H, 2005. Shiga toxin 2eproducing Escherichia coli isolates from humans and pigs differ in their Virulence profiles and interactions with intestinal epithelial cells. Appl Environ Microb 71:8855-63.

Thomas A, Cheasty T, Chart H, Rowe B, 1994. Isolation of Vero cytotoxin-producing Escherichia coli serotypes 09ab:H- and 0101:H- carrying VT2 variant gene sequences from a patient with haemolytic uraemic syndrome. Eur J Clin Microbiol 13:1074-6.

Troz-Williams LA, Mercer NJ, Walters LM, Maki AM, Johnson RP, 2012. Pork implicated in a Shiga toxin-producing Escherichia coli 0157:H7 outbreak in Ontario, Canada. Can J Public Health 103:322-6.

Tseng M, Fratamico PM, Bagi L, Manzinger D, Funk JA, 2014a. Shiga toxin-producing Escherichia coli in swine: the public health perspective. Anim Health Res Rev 8:1-13.

Tseng M, Fratamico PM, Bagi L, Manzinger D, Funk JA, 2014b. Shiga toxin- producing E. coli (STEC) in swine: prevalence over the finishing period and characteristics of the STEC isolates. Epidemiol Infect 8:1-10.

Villani F, Russo F, Blaiotta G, Moschetti G, Ercolini D, 2005. Presence and characterisation of verotoxin producing E. coli in fresh Italian pork sausages, and preparation and use of an antibiotic-resistant strain for challenge studies. Meat Sci 70:181-8.

Vimont A, Delignette-Muller ML, VernozyRozand C, 2007. Supplementation of enrichment broths by novobiocin for detecting Shiga toxin-producing Escherichia coli from food: a controversial use. Lett Appl Microbiol 44:326-31.

Wang F, Yang Q, Kase JA, Meng J, Clotilde LM, Lin A, Ge B, 2013. Current trends in detecting non-0157 Shiga toxin-producing Escherichia coli in food. Foodborne Pathog Dis 10:1-13.

Williams RC, Isaacs S, Decou ML, Richardson EA, Buffett MC, Slinger RW, Brodsky MH, Ciebin BW, Ellis A, Hockin J, 2000. Illness outbreak associated with Escherichia coli 0157:H7 in Genoa salami. Can Med Assoc J 162:1409-13.

Yan Y, Shi Y, Cao D, Meng X, Xia L, Sun J, 2011. Prevalence of Stx phage in environments of a pig farm and lysogenic infection of the field E. coli 0157 isolates with recombinant converting phage.Curr Microbiol 62:45864. 